\title{
El yo como "espíritu" (Geist) en la antropología de Edith Stein y de Karl Rahner
}

\author{
Fernando Berríos \\ FACULTAD DE TEOLOGÍA \\ PONTIFICIA UNIVERSIDAD CATÓLICA DE CHILE \\ fberríosm@uc.cl
}

\begin{abstract}
Resumen: Edith Stein y Karl Rahner fueron dos figuras decisivas del pensamiento católico del siglo XX. Desde mundos, biografías y motivaciones muy diversas, aunque también con importantes puntos en común, ambos destacaron por su esfuerzo de confrontación con categorías centrales del pensar moderno. En este contexto, "espíritu" (Geist) es una noción de especial interés, pues en ella ambos autores traslucen convicciones fundamentales de una antropología en sintonía con la modernidad, al mismo tiempo que reivindica, sin contradicción, el sentido de la trascendencia, expresado a través de la categoría "apertura" (Offenheit). A partir de un estudio anterior sobre este tema en la obra Hörer des Wortes (Oyente de la Palabra, 1941/1963) de Karl Rahner, en el presente trabajo se intenta una visión comparativa del mismo con los desarrollos de Edith Stein en Der Aufbau der menschlichen Person (La estructura de la persona humana, 1932).
\end{abstract}

Palabras clave: Espíritu - Antropología - Materia - Apertura.

Abstract: Edith Stein and Karl Rahner were two decisive figures of the XX century catholic thinking. With different backgrounds and motivations, yet bearing substantial points in common, both stood out for their efforts to deal with the main categories of modern thought. In this context, "spirit" (Geist) is a particularly interesting notion, for both authors display through it fundamental convictions of an anthropology in tune with modernity, which at the same time claims, free of contradiction, the sense of transcendence, expressed through the concept "openness" (Offenheit). Starting from a previous study on the matter, in Hörer des Wortes (Hearers of the Word, 1941/1963) by K. Rahner, the following paper aims to provide a comparative vision between the aforementioned work with Edith Stein's Der Aufbau der menschlichen Person (Structure of the human person, 1932).

Key words: Spirit - Anthropology - Matter - Openness. 
Estas dos figuras relevantes del mundo católico alemán del siglo XX, de las que no consta que hayan llegado a conocerse personalmente, compartieron, en todo caso, cada uno a su modo, un especial interés y un conocimiento muy profundo de la filosofía moderna y contemporánea desarrollada en Europa. Edith Stein, antes de su conversión al cristianismo católico, conoció a fondo la escuela fenomenológica de Husserl y adhirió muy profundamente a la idea de verdad que latía tras esa perspectiva filosófica ${ }^{1}$. Rahner se formó en el seno de la neoescolástica, pero siendo muy joven se abrió a los impulsos del pensamiento moderno, sin abandonar su especial aprecio por Tomás de Aquino ${ }^{2}$. En este interés se encuentran ambos proyectos intelectuales, contrastando, en cambio, por la postura de cada uno frente a la perspectiva trascendental de cuño kantiano. Todo este cúmulo de factores hace especialmente interesante confrontar el modo como Edith Stein y Karl Rahner construyen su propio concepto de espíritu, de clara resonancia moderna.

Otro aspecto nuclear del filosofar moderno al que ambos pensadores supieron abrirse es, claramente, la impronta antropológica. Para el teólogo alemán, se trataba del imperativo de un auténtico "recentramiento" antropológico como nota distintiva de todo un nuevo contexto cultural ${ }^{3}$. Para ahondar en ello, en lo que sigue se procederá a una confrontación de sendos textos de Stein y de Rahner que emplean el concepto espiritu en esa clave. Destacaré en cada caso los principales acentos de los autores sobre nuestro tópico, para identificar finalmente, a modo de conclusión, algunas grandes intuiciones comunes a ambos, como testimonio de un pensar cristiano en apertura a la modernidad.

1 Para una visión de conjunto de la vida y de la obra de E. Stein, cf. W. Herbstrith. El verdadero rostro de Edith Stcin (Encuentro. Madrid 1 990) y L. Elders (Ed.), Edith Stein: Leben, Philosophie, Vollend1mg (Naumann, Würzburg 1991).

2 Para una completa y a la vez concisa presentación del autor, su biografía y su pensamiento, destaco, entre una amplísima literatura, a A. Raffelt-H. Verweyen, Karl Rahner (Verlag C. H. Beck, München 1997) y a H. VorgrimLer, Entender a Karl Rahner. Introducción a su vida y su pensamiento (Herder, Barcelona 1988), Trad. de M. Villanueva Salas.

3 CF. K. Rahner, “Theologie und Anthropologie”, Schriften zur Theologie, Bd. VIII (Benzinger Verlag, Einsiedeln-Zürich-Köln 1967), 43-65. 
La base de este análisis será una sección específica del acápite III del capítulo VII de Estructura de la persona humana ${ }^{4}$, cuyo tema es "el alma como forma y como espíritu". Los dos primeros acápites del capítulo tratan sobre "El alma humana y la forma sustancial del hombre" (I.) y sobre "La esencia del espíritu" (II.). Las dos primeras subdivisiones del acápite III, 1 tratan sobre "La peculiaridad del alma como ser espiritual"s. Es conveniente recordar que en toda esta sección es determinante la precisión terminológica de E. Stein en relación al vocablo "espíritu" (Geist). Este puede traducir tres expresiones latinas: intellectus, mens, spiritus ${ }^{6}$. Las dos primeras designan "una parte del alma humana, no su totalidad" : Intellectus, la dimensión cognitiva del alma; mens, la parte racional, abarcante tanto de la inteligencia como de la voluntad y que se entiende como contrapuesta a la sensibilidad como parte "inferior" del alma.

En cambio, la expresión spiritus, cuya acepción es la que Edith Stein asume, se refiere al alma en su conjunto y como contrapuesta a "cuerpo"; pero no en sentido de "cuerpo vivo", sino solo como res extensa y material. En este sentido, el latín spiritus aparece como el equivalente del término griego pnéuma, "hálito", es decir, el aspecto esencial del espíritu que radica en su "falta de fijación, su ligereza, su movilidad". Así, para Edith Stein la noción de espíritu se refiere ante todo al concepto de persona o, como dice la autora, a la "estructura personal" que se manifiesta en la conciencia del propio ser y en la capacidad de apertura a otro ser, a lo distinto de sí, lo que a su vez "debe entenderse en el sentido de la

4 E. STEIn, Edith Stein Gesamtausgabe, Bd. 14: Der Aufbau der menschlichen Person - Vorlesung zur philosophischen Anthropologie [en adelante AmP] (Herder, FreiburgBasel-Wien 2004), 103-133. Trad.: Estructura de la persona humana (en adelante EPH), en E. Stein, Obras completas (Editorial Monte Carmelo/Ediciones El Carmen/Editorial de Espiritualidad, Burgos/Vitoria/Madrid 2002-2005), Vol. IV, 664-678.

AmP, 103-104/EPH, 678-679.

AmP, 99/EPH, 673s.

Para esta ubicación general me apoyo en M. DE LA MAZA, "Sobre el espíritu en Hegel y Edith Stein”, Teología y Vida, 56/2 (2015) 271-289.

8 AmP, 100/EPH, 674.

9 AmP, 103/EPH, 678. 
intencionalidad, de la captación de objetos" ${ }^{10}$, aunque de un modo específico. Sobre esto, reflexiona Stein:

"Cuando mi mirada resbala indiferente por las cosas que me rodean, no recibo nada en mí: reconozco la silla, la mesa y la pared como tales, pero no 'tengo' nada de ellas en mi interior. En cambio, cuando mi mirada se posa en una persona, esa persona, por regla general, no permanecerá indiferente" ${ }^{\prime 1}$.

El "ser espiritual" puede darse, para Stein, en diversos tipos de entes y en diversos grados: los "espíritus creados" y el "espíritu divino" ${ }^{12}$. Este es el único espíritu "puro" en sentido estricto, porque "es infinito, no está circunscrito a los límites del ser" ${ }^{13}$. Es acto puro y, sin embargo, a la vez "salida (Ausgehen) de si mismo". Esta actualidad pura es "plena posesión del propio ser" y al mismo tiempo "perfecta ligereza"; en otras palabras, una manera de ser acto puro que es "todo lo contrario de estático"14.

Por otro lado y siguiendo a Tomás de Aquino, Stein distingue, al interior los espíritus creados, a los "espíritus puros" -ángeles y demonios-, que son tales porque no están vinculados a un cuerpo, pero que son "finitos", a diferencia del espíritu divino, por su índole creatural, no eterna, y porque si bien se ha superado en ellos la contraposición entre espíritu y materia, sí experimentan aquella otra entre potencia y actualidad ${ }^{15}$. Ellos, precisa Stein, "no son inmutables, pero su ser natural se mueve libremente sin sujeción a ningún obstáculo exterior ni interior" ${ }^{16}$. En cambio, los espíritus finitos humanos se despliegan como almas esencialmente unidas a un cuerpo. La naturaleza humana es una unidad en que lo personal, la personalidad o la cualidad de ser persona, está determinada por la ley del espíritu. "El alma es espíritu", afirma nuestra autora, en el sentido de que

"es un ente bien consciente de su propio ser y abierto a otro ser, un ente que se tiene a sí mismo en su poder disponer libremente de sí, pero todo ello sin la ilimitación propia del espiritu puro [...], sino que al

\footnotetext{
AmP, 112/EPH, 687s.

AmP, 112/EPH, 688.

$A m P, 101$ s/EPH, 675s.

AmP, 101/EPH, 675.

AmP, 102/EPH, 676.

AmP, 102s/EPH 677.

M. De la Maza, "Sobre el espíritu...", 4.
} 
tomar conciencia de sí se encuentra como un ente ya constituido de determinado modo" 17 .

Para Edith Stein, en esta unidad de la naturaleza humana el alma espiritual tiene "un lugar central y dominante"18. Esto es así, dado que "el cuerpo es algo también sin el alma, pero es este cuerpo solo gracias a esta alma y en unidad con ella" ${ }^{19}$. Sin embargo $-\mathrm{y}$ esto es de especial interés en el pensamiento de la filósofa-, ello no equivale a afirmar que el alma determine toda la estructura óntica de la unidad de la naturaleza humana. En otras palabras, para nuestra autora el alma espiritual no debe ser equiparada con la forma sustancial de la misma, es decir, con el "principio estructural (Aufbauprinzip) del individuo humano como un todo" ${ }^{20}$. Y lo dice con terminología aristotélica-tomista: el alma es "forma del cuerpo" ${ }^{21}$. Sobre la base de estas consideraciones, este acápite III del capítulo VII de Estructura de la persona humana analiza y explica la "peculiaridad del alma como ser espiritual" desde la comprensión de la unidad e integralidad de la naturaleza humana y profundizando en la noción de fuerza (Kraft) como algo común del cuerpo y del alma. En este horizonte destaco ahora algunos aspectos centrales de la noción steiniana de espíritu, tal como los desarrolla en las dos subdivisiones restantes de este acápite III $^{22}$.

Edith Stein finaliza la subdivisión anterior de este acápite (2. La unidad de la fuerza) con la reflexión: "Todo el reino de los valores positivos es una fuente inmensa de fuerza anímica” ${ }^{23}$. Con ello se abren los límites de nuestra vida espiritual, hasta ahora reflexionada en el plano de las personas y del ser personal (Dios como espíritu puro, los espíritus puros finitos y las almas humanas en su índole espiritual). Los grandes valores (la bondad, la belleza...) no son "personas", ni tampoco "actos de personas". Pero si los consideramos como seres espirituales, nos abrimos a un nuevo tipo de ellos. Este sería el ámbito del "espíritu objetivo". Stein toma como ejemplo el caso de la belleza de un paisaje. Esa belleza irradia ciertas características ("clara, suave, pacífica”), y el que la

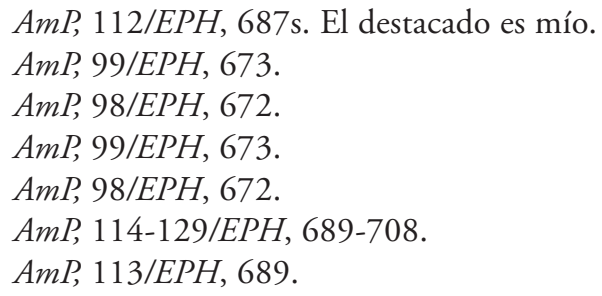


capta, puede acogerla y así "participar" de ella y de tales rasgos. Esta experiencia Stein la denomina un "estado del alma" y la entiende como "algo espiritual"24. No se trata de que lo primero sea ese estado del alma al que el objeto estético nos lleva, y luego, en un segundo momento, nosotros "proyectemos" dicho estado al objeto. La claridad y la suavidad las experimentamos como propiedades del paisaje contemplado y ello nos provoca un determinado estado de ánimo. Si luego cambiamos de estado interior por causa de las propiedades del paisaje, vivenciaríamos ese cambio "como procedente del paisaje mismo"25. Aquí habría que decir lo mismo que en relación a la figura del cuerpo humano, que está "llena de significado y que en ella nos habla el modo de ser espiritual del hombre". En las características físicas del paisaje, que nos impactan, reconocemos un sentido, de tal modo que en ellas también nos está hablando algo espiritual. Ahora bien, no por eso se transforman en personas, en seres personales, ni podemos atribuirles un alma. Pero tienen un "sentido espiritual", el cual radica en lo valioso que reconocemos en ellas y que puede penetrarnos y causarnos sentimientos positivos y superiores (alegría, elevación, entusiasmo....).

Con lo dicho, Stein refuerza su comprensión unitaria de la realidad toda: "el reino del espíritu abarca todo lo creado" y "todo lo que no sea espíritu puro ha de ser materia atravesada por el espíritu" ${ }^{26}$. Esta afirmación impele a aclarar la relación entre espiritu y forma. Dios, por ser espíritu puro, es, como ya se dijo, acto puro y, en consecuencia, forma pura, pues no hay en él diferencia entre lo configurado y lo configurante. Pero en el resto de los seres esto no es así, y habrá que constatar en ellos alguna forma de dualismo. En este contexto interesa estudiar las relaciones entre espíritu, forma y materia.

Cuando se opone la materia al espíritu y a la forma, nos debemos preguntar si materia significa lo mismo en ambas oposiciones. La respuesta de Edith Stein es no. En un sentido, materia es fuerza (Kraft); y en otro sentido es aquella materia que llena el espacio, el 'material' (Stoff). En ambos sentidos, la materia de suyo carece de forma, requiere ser "informada". Todo objeto, aunque no tenga algo de "espiritualidad personal", como un bloque de granito, sí está "informado", tiene una forma que

\footnotetext{
AmP, 114/EPH, 690.

AmP, 115/EPH, 690.

AmP, 115/EPH, 691.
} 
es más que una simple suma de cualidades sensibles. Tiene así un sentido que nuestro entendimiento puede captar en su dimensión simbólica (en este ejemplo concreto: firmeza inconmovible, estabilidad que inspira confianza) y en su dimensión práctica (todo lo que ha podido hacerse en el pasado y hoy con ese granito, por sus cualidades físicas). Ambos sentidos se corresponden internamente y remiten a algo que los trasciende: la sospecha o la percepción de que hay un espíritu personal detrás del mundo visible; que la materia informada es, de hecho, "materia atravesada por el espíritu". Y que si bien esa forma no es propiamente espíritu personal, es decir, no es alma, sí es sentido, que viene de un espíritu personal y habla a un espíritu personal interviniendo en su contexto vital. En esta perspectiva es legítimo hablar de "espíritu objetivo" 27.

Ahora bien, si incluso lo que parece más lejano del espíritu, el 'material' (Stoff), está también atravesado por el espíritu, es necesario aclarar la relación que se da entre la materia como fuerza (Kraft) con la forma y con el 'material' (Stoff). En los espíritus puros, incorpóreos, la fuerza se despliega con la propia vida, en su forma específica. Aquí la forma no es solo sentido, es espíritu personal y la fuerza es "posesión (Besitz) personal" 28 . Pero, ¿esta fuerza solo se da informada como ser personal, o se da también en los seres espirituales no personales a los que se ha adjudicado aquí el carácter de "espíritu objetivo"? Edith Stein responde afirmativamente. Por eso se ha hablado antes de las diversas fuentes de la fuerza del hombre. En todo caso, agrega, “todo lo que [el hombre] recibe en su interior puede incrementar su fuerza, pero también consumir al menos parte de la misma" ${ }^{29}$. En lo que respecta a la fuerza física, inmanente al 'material', hay que precisar que se activa o se actualiza en el movimiento; y lo que allí acontece no es vida personal-espiritual ni tampoco fuerza personal-espiritual, pero sí "guardan relaciones simbólicas y teleológicas con lo personal-espiritual", que son "accesibles al espíritu humano" ${ }^{30}$. De todo lo dicho hay que concluir que "no hay 'material' (Stoff) sin fuerza (Kraft)", es decir, que el ser de las cosas materiales es fuerza informada que se expresa en su concreto actuar y en su movimiento.

\footnotetext{
AmP, 117/EPH, 692s.

AmP, 117/EPH, 693s.

AmP, 117/EPH, 694.

AmP, 118/EPH, 695.
} 
Ello lleva a afirmar la unidad del espiritu y del 'material', y de la fuerza espiritual y física en el ser humano $(I I I, 4 \text {. })^{31}$. En todo este apartado final del acápite III del capítulo VII de Estructura de la Persona Humana, Edith Stein insiste en el carácter integral y unitario del ser humano. En primer lugar, que la fuerza natural del ser humano es una sola, aunque tenga diversas fuentes, materiales y espirituales. Con ello, en todo caso, no se suprime la diferencia entre espíritu y materia. El mundo material, por más "informado" que sea, es un mundo cerrado en sí mismo y unitario, y lo designamos naturaleza. Su unidad es la unidad de la eficiencia, que se manifiesta en movimientos y, más exactamente, en la unidad del movimiento. No hay en la naturaleza espiritualidad personal. Sus sustancias carecen de libertad para determinar su ser y su actuar. Por su parte, el mundo del espíritu, aunque no es "naturaleza" -porque en él no domina la necesidad de coacción-, también se rige por leyes; pero se trata de una legalidad propia de lo personal-espiritual, o de la "eficiencia espiritual" que brota de la libertad. "La persona espiritual es libremente activa (tätig)" ${ }^{\prime 2}$, en un actuar (Tun) que consiste en conocer y querer, y cuyos objetivos son, respectivamente, la verdad y el bien. El camino a estos objetivos está regido por una cierta legalidad, la "legalidad racional", que empero no es una coacción, pues el espíritu puede y debe plegarse a ella libremente.

El mundo espiritual no es un mundo cerrado en sí mismo. Su "legalidad" no afecta negativamente a esa impronta. Por el contrario, es propio de los espíritus personales su apertura a todo ser, especialmente a otras personas, en un contexto de comprensión. Captar al otro es comprenderlo. Y ello acontece en la con-vivencia con la actuación espiritual de otros y en la re-vivencia (Mit-und Nachleben), que es introducirse en el contexto vital (Lebenszusammenhang) de otros ${ }^{33}$. Se trata de una comprensión que no es meramente intelectual, sino que incluye la unidad en el querer y en el obrar. La diferencia de esta unidad con la unidad natural, es que en este caso se trata de una unidad consciente. Además, se puede constituir o disolver libremente.

Ahora bien, el ser humano es un ser de dos mundos: de la naturaleza y del mundo espiritual; de la ley de la coacción y de la ley de la libertad.

\footnotetext{
AmP, 118-120/EPH, 695-708.

AmP, 119/EPH, 696.

$33 \mathrm{AmP}, 119 \mathrm{~s} / \mathrm{EPH}, 696$.
} 
Ambos ámbitos se interpenetran (sich durchdringen) en él. El cuerpo vivo, que es el cuerpo humano, es un cuerpo material, aunque dominado por el espíritu. No es solo materia informada, sino cuerpo "atravesado por el alma espiritual" ${ }^{4}$. Ello se traduce en su modo de disponer sobre la fuerza corporal: "la libre acción espiritual surte efecto sobre el mundo material" ${ }^{35}$. En el ser humano la fuerza corporal se puede consumir no solo en actividades propiamente corporales, sino también en el ejercicio de la voluntad. Muchas veces es el impulso (y el gasto de energía implicado en el uso) de la voluntad, lo que extiende las fuerzas corporales más allá de sus límites, para alcanzar un objetivo. Pero también se lo puede percibir al revés: la primera decisión en pos de determinados objetivos es un acto racional, pero finalmente el ser humano "no puede alcanzarlos sin la colaboración de su cuerpo" ${ }^{36}$. En definitiva, el frescor o el cansancio son estados vitales de carácter a la vez corporal-anímicos.

A partir de estas consideraciones fundamentales, Edith Stein pasa a precisar una serie de distinciones, sobre todo en relación a actos puntuales y disposiciones más permanentes en el ser y en el hacer humanos (actos, estados, potencias, facultades, disposiciones...); toda una pluralidad que permite hablar de "fuerzas", aunque en definitiva la fuerza del ser humano es una sola. En esta perspectiva, se destaca la función de la voluntad como integradora de toda la fuerza disponible en el organismo. La voluntad "tiene la posibilidad de querer por encima de su propia naturaleza y de los límites que esta le marca" ${ }^{37}$, aunque no es menos importante la consideración de las disposiciones naturales y de la "inclinación" (Neigung) para la configuración de las potencias en general ${ }^{38}$.

Hacia el final del apartado III,4 Edith Stein vuelve a un tema fundamental, en que se revela su comprensión más profunda de la noción de espíritu. Entiende que la "la vida del alma es una vida espiritual: conocer, sentir, querer", y que en esa vida espiritual el alma manifiesta su vocación más profunda: la apertura a otro ser espiritual, "del que puede fluir fuerza hacia ella", sobre todo si ese otro puede ser el espíritu infinito de $\operatorname{Dios}^{39}$. Por lo mismo, se hace necesario precisar los términos

\footnotetext{
AmP, 120/EPH, 697.

AmP, 121/EPH, 698.

AmP, 122/EPH, 699.

AmP, 127/EPH, 705.

AmP, 126s/EPH, 704.

AmP, 128/EPH, 706.
} 
y la relación mutua entre espiritu y alma ${ }^{40}$. Pero, sobre todo, a la autora le interesa destacar el significado del alma como "centro (Zentrum) de la existencia (Dasein) humana", como lugar de las vivencias más íntimas y profundas, y a la "fuerza anímica" (seelische Kraft) como la capacidad de vivir esas experiencias en su más honda radicalidad. Pero, de nuevo, hay que decir que esa hondura de la fuerza anímica no es separable "del todo que siente, piensa y quiere, y que hace del cuerpo un cuerpo humano vivo y dotado de configuración personal. Para designar esa instancia interior, nuestro idioma [¡el alemán!], dispone del término 'ánimo' (Gemüt)" ${ }^{41}$.

Si se refiere a esa instancia con la palabra "alma", se entiende específicamente el "alma del alma [...], aquella región en la que el alma está cabe sí misma (bei sich selbst)" "42. Esto remite a las relaciones entre alma (Seele), ánimo (Gemüt) y voluntad (Willen). El alma recibe en el ánimo lo que le viene desde fuera; en el ánimo el alma toma postura frente a aquello; finalmente, se da el paso del ánimo a la voluntad, "que va más allá del alma y configura al ente mismo" “3. Igualmente estrechas son las relaciones entre el ánimo y el entendimiento (Verstand), pero lo más importante para Stein es insistir en que el alma es una y la misma en el conocer y en el querer; una y la misma que en el ánimo está "cabe sî" y de ese modo se confronta (auseinandersetzt) interiormente con aquello que acoge en sí misma. Concluyendo, cabe establecer una contraposición entre espíritu y alma, pero no una relación de mutua exclusión: "El 'alma del alma' es algo de índole espiritual; y el alma como un todo es un ser espiritual" "44, y su característica principal es el hecho de tener una interioridad (Inneres) en su centro, desde la cual debe salir para encontrarse con objetos y hacia la cual debe traerlos una vez adquiridos, y también, desde ese mismo centro interno, darse hacia afuera. En esto radica el centro de la existencia humana.

En el apartado IV del capítulo VII, Edith Stein bosqueja una "síntesis de lo expuesto acerca del individuo humano", para luego pasar, en el capítulo siguiente, a la consideración de la persona humana como ser

\footnotetext{
$A m P, 128 s / E P H, 706-708$.

AmP, 129/EPH, 707.

AmP, 129/EPH, 707.

AmP, 129/EPH, 707.

AmP, 129/EPH, 708.
} 
social, es decir, como un ente cuya consideración como individuo aislado sería una mera "abstracción", dado que lo propio de su estructura es "apuntar a lo que se encuentra fuera de ella misma” ${ }^{45}$, por razón de su esencial apertura.

\section{Karl Rahner (1904-1984): espíritu en Oyente DE LA PALABRA46}

En el pensamiento de Karl Rahner, "espíritu" es en primer término una noción de índole antropológica. En sus aspectos esenciales, el autor la desarrolló en su obra Geist in Welt (Espíritu en el mundo), que fue en su origen una tesis doctoral en filosofía que nunca llegó a ser formalmente presentada en la Universidad de Freiburg, Alemania, debido a reparos del profesor guía, Martin Honecker, sobre el tipo de interpretación de la metafísica tomista contenida en ella. De todos modos, el libro fue publicado en 1939, causando una gran impacto.

La profundización de las implicancias de dicha interpretación de la metafísica tomista para una filosofía de la religión, Rahner la llevó a cabo en una segunda obra, Hörer des Wortes (Oyente de la Palabra), publicada en $1941^{47}$, a partir de algunos materiales previos ${ }^{48}$. En esta segunda obra Rahner manifiesta su intención de avanzar, siguiendo los impulsos de Espiritu, en el desarrollo de una reflexión filosófica que, sin dejar de ser tal en su propia especificidad, se oriente finalmente a la fundamentación de una cuestión teológica: el acontecimiento de la Revelación del Dios de Jesucristo, del Dios de la Biblia y, sobre todo, de las condiciones de

$45 \quad A m P, 133 / E P H, 711$.

46 El contenido de este apartado es una versión extractada y resumida de mi trabajo: "Noción de 'espíritu' en Karl Rahner: una perspectiva de filosofía de la religión", Teología y Vida, Vol. LVI/3 (2015) 197-227. El foco esta vez es la comparación de la conceptualización rahneriana con la de Edith Stein.

47 Para la citas textuales de esta obra indicaré primero, con la sigla $H W$, la paginación de la versión original alemana de la segunda edición (de 1963, a cargo de J. B. Metz) en las Karl Rahner Sämtliche Werke (SW), Bd. 4: "Hörer des Wortes. Schriften zur Religionsphilosophie und zur Grundlegung der Theologie”, A. Raffelt (ed.) (Benzinger-Herder, Düsseldorf-Freiburg i.Br. 1997, y luego, con la sigla OP, la de la traducción castellana de dicha edición (Oyente de la Palabra - Fundamentos para una filosofía de la religión [Herder, Barcelona 1967]). Utilizo esta traducción, pero la corrijo cuando me parece pertinente, indicando ello en cada caso.

48 Cf. el texto resumido de las conferencias de Rahner en las "Semanas de la escuela superior de Salzburg" de 1937, y de una homilía pronunciada por él durante el evento, en $S W$, Bd. 4, 285-295. 
posibilidad de este acontecimiento en el ser humano y en su ámbito existencial histórico y mundano.

La afirmación central de la antropología que Rahner desarrolla como fundamento de una filosofía de la religión es, precisamente, que el ser humano es, de por sí, "espíritu". El capítulo V de Oyente de la Palabra desarrolla los aspectos centrales de esta afirmación. Este capítulo se titula "El ser humano como espíritu" (Der Mensch als Geist), expresión que resume el contenido central de un segundo presupuesto del libro para una posible revelación, a saber, que el ser humano debe tener una "apertura” (Offenheit) a la automanifestación de Dios en su palabra (logos), como "fundamento absoluto de los entes y del conocimiento del ser" ${ }^{49}$. Recordemos que el primer presupuesto es el contenido de la primera tesis de ontología general, en la cual Rahner basa todo el desarrollo del contenido del libro ${ }^{50}$ : la esencia del ser es la unidad originaria de conocer y ser conocido como "ser-cabe-si", subjetividad o luminosidad". Lo que está a la base es el principio escolástico tomasiano de la identidad de conocer y ser, de lo cual se deduce una comprensión del conocer como un acontecimiento ontológico, de subjetividad, más que como un acto "intencional", en el sentido de un simple encuentro del cognoscente con un objeto que le es del todo ajeno. Conocer es ser y ser es conocer, es decir, un movimiento en el que, al reconocer a otro, al objeto, el sujeto cognoscente "retorna" sobre sí mismo, a su subjetividad como un "estar-consigo".

$49 H W, 15 / O P, 20$.

50 Es necesario hacer presente que el contenido de Hörer des Wortes está articulado como el entretejido de tres "tesis de ontología general", a las que corresponden tres "tesis de antropología metafísica". La segunda tesis de ontología general plantea que el ser absoluto de Dios es, frente al ente finito, el ser libre (cf. $H W, 143 / O P, 124$ ); y la tercera, que "todo ente puede ser hecho presente en el horizonte del fenómeno mundano, mediante la palabra" (HW, 229/OP, 199). Las tres tesis de antropología metafísica, que corresponden, cada una, a las tres tesis de ontología general, son las siguientes: 1) "El ser humano es la absoluta apertura al ser en general, o, para decirlo con una sola palabra: el ser humano es espíritu. La trascendencia hacia el ser es la constitución fundamental (Grundverfassung) del hombre" (HW, 83/OP, 73s). 2) "El ser humano es el ente que con un libre amor se halla ante el Dios de una posible revelación" ( $H W, 163 / O P, 141)$; y 3$)$ "El ser humano es el ente que en su historia debe prestar oído a la revelación histórica de Dios, que posiblemente advendrá en forma de palabra humana” ( $H W, 249 / O P, 213)$.

$51 \quad H W, 65 / O P, 58$. 
Esto implica que el ser es "preguntable" (fragbar) y, por lo tanto, "cognoscible" (erkennbar); pero además, necesariamente, "cuestionable" (fraglich), es decir, que hay una cierta distancia entre lo preguntado y aquel que plantea la pregunta por el ser, de tal manera que esta sea una pregunta real y la respuesta no esté ya dada de antemano. En todo caso, que el ser sea "cognoscible" indica la unidad primigenia de ser y conocer. A esto precisa Rahner: "el preguntante [...] solo puede saber del ser [...] en cuanto él mismo es lo sabido [...] Y sin embargo, el que pregunta 'no' puede 'ser' el ser por el que pregunta [...] El ente que pregunta es en este sentido no ser" 52 . Por otra parte, "este ente que pregunta debe 'poseer' (besitzen) ser, de ese al que se aplica la primera tesis" ${ }^{\prime 3}$. El punto, para Rahner, siguiendo una intuición tomasiana, es que esto se da "analógicamente", pues hay diversos grados de "posesión del ser" (Seinshabe). Con esto nuestro autor está proponiendo, como precisaremos luego, una relectura de la doctrina tomasiana de la analogía del $\operatorname{ser}^{54}$.

Ahora bien, la índole "espiritual" del ser humano, es decir, su esencial apertura, tiene que ser a priori (en el sentido específico de "condición de posibilidad"), para que dicha palabra divina, si es dicha, pueda ser oída $^{55}$. De ahí -hay que reiterarlo- el sentido de la primera tesis de una antropología metafisica en esta obra de Rahner: "el ser humano es la absoluta apertura al ser en general, o, para decirlo con una sola palabra: el hombre es espíritu. La trascendencia hacia el ser es la constitución fundamental (Grundverfassung) del ser humano" ${ }^{56}$. En este sentido, el ser humano es una pregunta, una pregunta por el ser, y no podría no serlo. Veamos esto con algo más de detalle.

Punto de partida: el porqué de la necesidad humana de la pregunta por el ser (o el ser humano como "sujeto"). La pregunta por el ser en general surge necesariamente en la existencia humana, en todo pensar y en todo obrar. Pero esta pregunta lleva implícita la respuesta, esto es, el conocimiento, o un cierto conocimiento, del ser en general. En este trance el ser humano es "sujeto", es decir, "está en un mundo de entes que se le

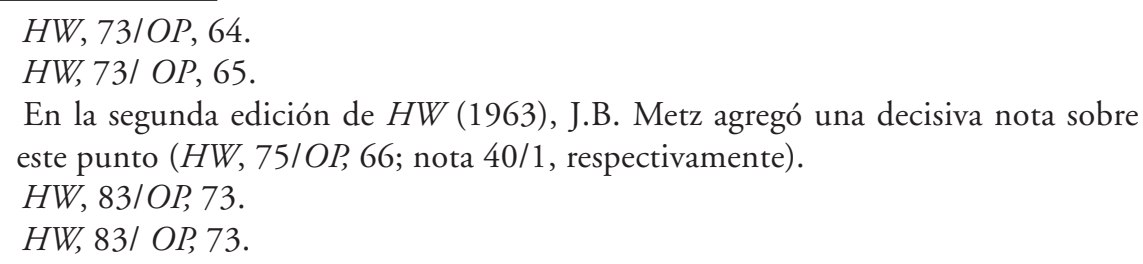


presentan como sus objetos" 57 . No es un objeto entre otros. Él "posee un mundo, con el que se enfrenta y del que se destaca o distancia pensando y obrando" 58 . En esa relación con las cosas del mundo, el ser humano las "juzga" (beurteilt) y así las distingue de sí. Este juicio expresa la objetivación del objeto, pero en esa misma objetivación se manifiesta "el modo de estar el ser humano en sí mismo escientemente (wissend)" ".

¿Cuál es el fundamento último de la posibilidad del ser humano de enfrentarse con esta modalidad de estar en sí mismo escientemente? En otras palabras, ¿cuál es la "condición trascendental apriórica de la posibilidad (apriorische transzendentale Bedingung der Möglichkeit) de esta subjetividad?" ${ }^{0}$. Aquí el autor recoge una categoría tomasiana: el acto de conocer como reditio in seipsum. Tomás de Aquino, en el capítulo IV,11 de la Summa contra gentes se refiere a la reditio rei in seipsam, el retorno de la cosa a sí misma -en este caso, del sujeto en el acto de ser-conocer-, pero también a su variación como constitutiva de los diferentes "niveles del ser". Esto es así, dado que la unidad de ser y conocer no se da de modo unívoco, sino analógico. El único que es absoluta 'posesión del ser' -en identidad del ente con su ser- como un "estar-consigo" es el ente que es "el puro ser", o sea, Dios ${ }^{61}$. Pero ello no se da así en el caso del ser humano, el que, en cuanto "espíritu finito" (endlicher Geist), es de por sí una pregunta abierta y necesaria por el ser. Este preguntar es parte de su estructura fundamental y ello constituye el punto de arranque necesario para desarrollar y comprender la afirmación: el hombre es espíritu.

En todo juicio se conceptualiza, es decir, se aprehende un "esto" particular bajo un concepto universal. Así el sujeto "separa" de sí a este "esto" como su objeto. De ese modo realiza el sujeto ese estar en sí mismo escientemente. El núcleo de esta problemática en la metafísica tomista se denomina "abstracción". Abstraer consiste en desgajar o separar el "qué", la quiddidad, del individuo particular en que se da. En este sentido, la abstracción es el conocimiento de lo ilimitado del "qué" que

\footnotetext{
$57 \quad H W, 83 / O P, 74$.

$58 H W, 74 / O P, 84$.

$59 H W, 87 / O P, 76$.

$60 H W, 87 / O P, 77$.

${ }^{61} H W, 87$, nota $46 / O P, 77$, nota 7.
} 
se da en un individuo concreto y que aparece así como "una nota que se extiende mucho más allá" del mismo ${ }^{62}$.

En este punto se plantea el rol determinante de la noción de "anticipación" (Vorgriff). El acto que aprehende el "esto", la quiddidad ilimitada, es un acto que "se extiende a más de lo que el individuo es" ${ }^{63}$. Aquí el texto de Oyente de la Palabra inserta la nota 49 (en la edición alemana) o 2 (en la traducción castellana), en la que se precisa el concepto de "anticipación" (Vorgriff) como denominación de ese "extenderse". El "más" al que se refiere, debe entenderse, en esta perspectiva, como "horizonte y fundamento último (Horizont und gründerder Grund) de los objetos posibles y de su encuentro con ellos (...) la conciencia capta su objeto particular en una 'anticipación'... dirigida al ser" ${ }^{64}$. Así,

"esta anticipación es la condición de posibilidad del concepto universal, de la abstracción (...) Es una 'facultad' (Vermögen) -dada a priori con la esencia humana- del automovimiento dinámico (der dynamischen Selbstbewebung, cf. nota 51 [en la edición alemana] o 4 [en la traducción castellana]) del espíritu hacia el ámbito absoluto de todos los objetos posibles (...) En tal 'anticipación' se conoce ya siempre en cierto modo el objeto particular bajo el horizonte del ideal absoluto del conocimiento" 65 .

Para Rahner, en la anticipación (de lo absoluto e ilimitado) se da, precisamente, la experiencia trascendental del limite. Se plantea entonces la pregunta: ¿qué es exactamente esa "totalidad", aquello a lo cual trasciende el conocimiento "anticipante" humano cuando aprehende el objeto particular? En otras palabras, ¿¿de qué modo tiene lugar la anticipación, cuyo término es el "no" de la experiencia trascendental del límite? El conocimiento humano se dirige primariamente al ente, es decir, al "sí", al ser y no a la nada. Si hablamos de anticipación, se entiende que esta se dirige al "si". En consecuencia, es "posible y legítimo (können-dürfen) no interpretar la trascendencia como una trascendencia a la nada" ${ }^{66}$. La anticipación, por el contrario,

\footnotetext{
$62 \quad H W, 91 / O P, 79$.

$63 H W, 91 / O P, 80$ abajo.

$64 H W, 93 / O P, 80$.

$65 H W, 93 / O P, 81$.

$66 \quad H W, 97 / O P, 84$.
} 
“apunta a lo ilimitado (...) es en sí misma la negación de lo finito” (...), es "condición de posibilidad del conocimiento de lo finito (porque), al superarlo y trascenderlo, eo ipso pone de manifiesto su finitud. Por tanto, el sí que se da a lo de suyo ilimitado posibilita la negación, y no al revés (...) La ilimitación positiva del horizonte trascendental del conocimiento humano muestra ya por sí misma la finitud de todo lo que no cubre completamente este horizonte. No es que la nada 'nihilice', sino que la in-finitud del ser al que apunta la 'anticipación' desvela (enthült) la finitud de todo lo inmediatamente dado" ${ }^{37}$.

Con ello se afirma, finalmente y con la misma necesidad, a Dios como "el ente de la absoluta 'posesión del ser' (Seinshabe)" ${ }^{68}$. No es que la anticipación ponga a Dios como objeto del espíritu, pues aquella es solo condición de posibilidad del conocimiento objetal. Pero en la anticipación sí se afirma, aunque no se represente propiamente, la existencia de un ente de absoluta 'posesión del ser', esto es, Dios ${ }^{69}$, puesto que la positividad del ser es la que posibilita el 'no' de la diferencia ontológica inacabada (unvollendet), y no al revés. Por esto se puede decir que la 'anticipación' tiene por meta (zielt auf) a Dios"70. Pero no como objeto, sino como horizonte absoluto. En este sentido, la anticipación no es una demostración a priori de (la existencia de) Dios (Gottesbeweis); la anticipación y su amplitud solo pueden ser conocidas (...) "en la aprehensión (Erfassung) a posteriori de un ente real, cuya condición necesaria constituyen" ${ }^{71}$. La afirmación de la finitud de un ente exige, como condición de posibilidad, "la afirmación de la existencia de un ens absolutum, afirmación ya implícita en la 'anticipación' del ser en general, gracias a la cual se conoce como tal la limitación del ente finito"72.

Todo lo anterior lleva a Rahner a definir el "lugar" en que el ser humano puede y debe articular su ser espiritu. Podemos decir que para Rahner la realización del ser humano como espíritu es algo que tiene que ver ante todo con "el lugar del libre mensaje de Dios" (título de la parte $4^{\text {a }}$ de Hörer des Wortes). Dios solo puede revelar lo que el ser humano puede oír. Por lo tanto, para encontrar ese "lugar" de la posible revelación

\footnotetext{
$H W, 97 / O P, 84$.

$H W, 99 /$ OP, 86.

$H W, 99 / O P, 86$.

$H W, 99$ s/ OP, 86.

$H W, 101 / O P, 87$.

$H W, 101 /$ OP, 87.
} 
es necesario determinar lo específicamente humano de la trascendencia humana al ser absoluto. Todo este libro aparece, así, como una antropología metafísica entendida como condición de posibilidad y fundamento de una eventual y, ante todo, libre autocomunicación de Dios por la Palabra. No basta el enunciado abstracto de que el ser humano es "espíritu finito" (su trascendencia); hay que precisar, además, "la forma concreta" (bestimmten Weise) en que lo es $^{73}$. Y la respuesta, en lo inmediato, es que el ser humano es espíritu como acontecimiento que se da en el mundo material (capítulo X) y en la historia (capítulos XI a XIII). Materialidad e historicidad constituyen el núcleo del "lugar" de dicho acontecimiento, leído aquí específicamente en clave de filosofía de la religión.

Epílogo: LA NOCIÓN DE ESPÍRITU COMO EXPRESIÓN DE LA APERTURA RADICAL DEL SER HUMANO A LA TRASCENDENCIA

Finalmente, recojamos brevemente algunos elementos comunes en las reflexiones antropológico-filosóficas de estos dos pensadores que desde el horizonte compartido del cristianismo católico, aunque en contextos e itinerarios vitales e intelectuales muy diversos, supieron abrirse a los impulsos del pensar moderno.

Ambos recogen la noción de "espíritu" para describir el yo o la subjetividad humana y, en esa perspectiva, también los dos acentúan la apertura -al otro, al ser en general, a Dios- como rasgo principal de esa subjetividad personal. De gran interés - pero en todo caso objeto de un estudio aparte- sería indagar en detalle acerca de la fuente última desde donde cada uno tomó el término espíritu, Geist, en esta significación básica. Por de pronto podemos postular que el camino a recorrer debería ser, al menos en un primer momento, la indagación de las influencias filosóficas que más claramente se advierten en ellos. En el caso de Edith Stein, habría que revisar su itinerario en el ámbito de la fenomenología, primero como discípula de Edmund Husserl y como su asistente en la cátedra de Friburgo ${ }^{74}$, pero también en la evolución de su propio pensamiento en el contexto de su conversión al cristianismo católico y de su encuentro con la filosofía escolástica mediante su descubrimiento

\footnotetext{
$73 H W, 173 / O P, 151$.

74 E.STEIn, "WasistPhänomenologie?", en Wissenschaft/Volksbildung-Wissenschaftliche Beilage zur Neuen Pfälzischen Landes-Zeitung 5 (1924). Republicado en Theologie und Philosophie 66 (1991) 570-573.
} 
del pensamiento de Tomás de Aquino ${ }^{75}$. En el caso de Karl Rahner, el asunto tiene su propia complejidad, dado que en su pensamiento confluyen diversas vertientes filosóficas: por de pronto, la metafísica del conocimiento de Tomás de Aquino, releída con categorías del análisis trascendental kantiano, a su vez con apoyo en los desarrollos del jesuita belga Joseph Maréchal, y la antropología trascendental desde allí concebida; pero también la ontología fundamental del M. Heidegger de Sein und Zeit (1927), que agrega el componente existencial y refuerza la categoría historicidad (ya aportada, a su modo, por Tomás de Aquino) en dicha antropología ${ }^{76}$. Finalmente -hay que decirlo-, Oyente de la Palabra es expresión de una comprensión teológica -y más exactamente, teológica-fundamental- de la trascendencia de la condición humana en su más profunda radicalidad. En ambos autores, en todo caso, la noción de espíritu viene a aportar a una antropología que, sin renunciar a la centralidad del sujeto personal, tan cara a toda la tradición moderna, no concibe esa centralidad como un autocentramiento, sino, por el contrario, como la apertura radical de ese mismo sujeto al ser en sus diversas manifestaciones: el mundo, los otros, el Otro.

Ambos, también, conciben el espíritu, en cuanto noción antropológica, dentro de un marco de comprensión unitaria de lo humano. Para Edith Stein, lo importante en este punto no es precisar exactamente qué es espíritu y qué es materia, sino más bien dar relevancia a la mutua confluencia de ambas dimensiones en la realidad humana una. Para la filósofa, el espíritu realiza su sentido abarcando todo lo creado, precisamente porque es apertura y se actualiza comunicando a la materia esa apertura; y por otra parte, lo que no es espíritu puro apunta siempre, de por sí, a ser "materia atravesada por el espíritu". De esta su convicción de la unidad de lo humano y luego de mostrar la índole espiritual del alma, puede llegar a la conclusión de que "el cuerpo es algo también sin el alma, pero es este cuerpo solo gracias a esta alma y en unidad con ella" ${ }^{7}$.

75 E. Stein, "Husserls Phänomenologie und die Philosophie des hl. Thomas v. Aquino: Versuch einer Gegenüberstellung", Jahrbuch für Philosophie und phänomenologische Forschung. Ergänzungsband (1929) 315-338.

76 Cf. F. Berríos, "El método antropológico-trascendental de Karl Rahner como hermenéutica teológica del mundo y de la praxis", Teología y Vida, Vol. XLV/2-3 (2004) 411-437, esp. 420-427 y nota 34 con referencias bibliográficas sobre este aspecto.

77 Cf. la cita de la nota 19. 
En el caso de Rahner, y como ya lo hemos indicado, uno de los principales objetivos de Oyente de la Palabra es, precisamente, mostrar que el ser humano no tiene otro "lugar" que el mundo material e histórico para realizar su índole espiritual, dado que su facultad de conocer y, de paso, de realizar en ello su subjetividad, está necesariamente mediada por la sensibilidad. Aquí también es evidente el influjo de Tomás de Aquino y, más exactamente, de su doctrina de la conversio ad phantasmata ${ }^{78}$.

Finalmente, es especialmente destacable el que ambos autores precisan que la apertura del espíritu humano acontece en el mundo y en la historia como espacio de libertad. En el contexto de la afirmación de "la unidad del espíritu y del 'material' (Stoff), y de la fuerza espiritual y física en el ser humano"79, Edith Stein destaca el libre actuar que caracteriza a la persona espiritual, la que en su querer y en su conocer se orienta de por sí, con "una cierta legalidad" -que no es, empero, coacción-, a la verdad y al bien ${ }^{80}$. Esta orientación marca, a su vez, la índole propia de la apertura del espíritu. De otro modo, la antropología rahneriana está marcada por este mismo acento: la apertura "trascendental" que caracteriza al ser humano se realiza no sin autoposesión, es decir, no sin un acto de realización de la subjetividad, aunque ello acontece en un encuentro con aquel que lo impele y lo convoca a una respuesta que no puede ser, por lo demás, meramente pasiva. La anticipación (Vorgriff) le posibilita una existencia a partir de una pregunta que no es puro vacío, sino que, en cierto modo, le da las herramientas básicas para disponerse de un modo activo y necesariamente libre al ser y, en último término, a Aquel que es la "absoluta posesión del ser", lo que concretamente se despliega como existencia interpelada por una posible -pero ante todo libre- Palabra.

Por último, aunque al parecer la principal diferencia entre Stein y Rahner es la toma de postura fundamental de cada uno frente al pensar trascendental kantiano, me parece que, con todo, en ambos está la convicción de que la índole espiritual del sujeto o del yo es expresión de un "centro" personal, en el cual y a partir del cual es posible realizar el sentido de la existencia humana como situada en el mundo y en la historia. Da que pensar, en este sentido, que tanto en Edith Stein como en

\footnotetext{
78 Cf. cf. $S$. Th 1 q.86 a.1.

79 Cf. la cita de la nota 31.

80 Cf. la cita de la nota 32.
} 
Karl Rahner está presente la noción tomasiana de una reditio o un estar "cabe sí" (bei sich sein) del sujeto en cuanto espíritu, como modalidad concreta de la realización de su apertura y de su relación con el otro y con lo que lo trasciende. Esto implica una afirmación muy radical de la centralidad del sujeto, pero por otra parte se acentúa el que, como ya lo hemos indicado, esa centralidad subjetiva se constituye, precisa e indefectiblemente, a través de un salir de sí, de un abrirse al mundo y al otro, como camino a una auténtica autoposesión. Por lo mismo, es esta convicción antropológica básica la que hace que para ambos pensadores, aunque desde perspectivas distintas, la índole espiritual del yo ("el alma del alma”, el núcleo del sujeto) constituya también, a fin de cuentas pero inseparablemente y en el centro mismo de su ser, la condición de posibilidad de un encuentro con la libre iniciativa salvífica de Dios. 